\title{
HOLOCENE VARIATION IN SPATIAL SCALES OF VEGETATION PATTERN IN THE UPPER GREAT LAKES ${ }^{1}$
}

\author{
Lisa J. GraumLich \\ Laboratory of Tree-Ring Research, University of Arizona, Tucson, Arizona 85721 USA \\ Margaret B. Davis \\ Department of Ecology and Behavioral Biology, University of Minnesota, Minneapolis, Minnesota 55455 USA
}

\begin{abstract}
While continental-scale patterns of vegetation change during the Holocene clearly record the influence of climatic change, the factors governing change at the landscape scale are less clearly defined. In order to characterize the scales of processes determining vegetation patterns during the Holocene, we analyzed a network of 52 pollen sites in the upper Great Lakes region. Pollen percentage data for three dominant tree genera (pine, Pinus; oak, Quercus; birch, Betula) were interpolated from samples bracketing four target years $(500,2500,4500$, and $6500 \mathrm{yr} \mathrm{BP})$.

Smoothed isopoll maps of taxon abundance for each target year show broad trends in pollen abundance that correspond to climatic gradients. Residuals, representing the deviation of each pollen datum from the smoothed value, indicate the amount of spatial variation in pollen abundance independent of that already modeled as a broad gradient. The three genera differ in the magnitude and pattern of residual variation. Oak residuals are relatively small in magnitude, while pine and birch residuals are relatively large and show greater local variability in sign and magnitude. This indicates local variability in tree abundance, as pollen of all three taxa is readily dispersed by wind. Spatial correlograms, which summarize the strength of spatial autocorrelation as a function of distance between pairs of sites for a given taxon, were calculated separately for each target year and allow the quantification of the dominant scale of variability of each taxon. Oak correlograms corroborate the mapped data in indicating the dominance of region-wide trends. In contrast the birch and pine correlograms indicate that factors operating at scales of 150 to $300 \mathrm{~km}$ are as important as region-wide trends in governing pollen abundances. The structure of the correlograms for birch and pine pollen changes through time, with birch showing a more patchy spatial pattern in the mid-Holocene (4500 and $6500 \mathrm{yr}$ BP) as compared to the late-Holocene (500 and $2500 \mathrm{yr}$ BP). Pine, in contrast, shows a more strongly autocorrelated pattern in the mid-Holocene. Our results suggest that substrate, an environmental constraint on vegetation at scales of tens to hundreds of kilometres, has been important in governing the spatial distribution of birch and pine in the upper Great Lakes region. The changing distribution of birch and pine is attributed, in part, to changes in the relative abundance of ecologically dissimilar species within these genera. Further, these observations suggest that spatial scales of tree abundances are dynamic and that constraints imposed by substrate vary in importance in response to long-term climatic variation.
\end{abstract}

Key words: Betula; climatic variation; Holocene vegetation patterns; landscape ecology; Michigan; paleoecology; Pinus; pollen-based vegetation reconstruction; Quercus; spatial autocorrelation; spatial variation in pollen abundance; Wisconsin.

\section{INTRODUCTION}

Mapped summaries of vegetation change in the forests of the upper Great Lakes over the last $10000 \mathrm{yr}$ indicate two broad-scale changes in regional forest composition (Bernabo and Webb 1977, Davis 1981, Webb et al. 1983a, Davis et al. 1986). First, the ecotone between mixed forest and deciduous forest moved steadily northward from $11000 \mathrm{yr}$ BP to $6000 \mathrm{yr} \mathrm{BP}$,

${ }^{1}$ Manuscript received 25 November 1991; revised 15 June 1992; accepted 7 July 1992. and retreated southward from $6000 \mathrm{yr}$ BP to the present (Webb et al. 1983a). This change is recorded by maps of oak and pine pollen percentages. Second, an eastwest gradient in floristic composition developed in the upper Great Lakes region between 7000 and $5000 \mathrm{yr}$ BP. During that period, beech, hemlock, and birch began to increase in abundance or expand their westward ranges, continuing to do so through the late-Holocene (Webb et al. 1983a, Davis et al. 1986). These two vegetation trends imply increasing warmth and dryness from early- to mid-Holocene time and subsequent reversion to cooler, more moist climates (Bartlein et al. 1984, Webb et al. 1993). Rising water tables 
(Miller and Futyma 1987) and higher lake levels (Webb et al. 1993) also indicate increased moisture in the midand late-Holocene.

Fine-scale variations in the broad-scale patterns of vegetation change owing to climatic forces are usually apparent in a network of proximate sites. Such local variations often correspond to local (fine-scale) patterns in substrate (Brubaker 1975, Jacobson 1979, Bernabo 1981, Woods and Davis 1989). Generally, pollen assemblages vary with substrate in a manner that is largely in accordance with our knowledge of modern soil-vegetation relationships. Of particular interest to the current study is Brubaker's (1975) conclusion that the patterning of forest communities in northern Michigan was related to soil textural differences. She observed that the spatial scaling of the resulting mosaic changed configuration under differing climatic regimes. During the warm and dry mid-Holocene $(\approx 8000$ to $5000 \mathrm{yr} \mathrm{BP}$ ), unique forest communities existed on each of the three main substrate types (clayey till, fine outwash, and coarse outwash) within her $25 \times 40 \mathrm{~km}$ study area. The modern mosaic of forest communities did not become established until after 3000 yr BP, when the composition of the forests on fine outwash and till converged. Her results imply that vegetation scaling factors (the "grain" of the landscape) can change under differing climatic conditions and that community differentiation by soil type may or may not occur, depending on climatic conditions. In this paper we explore the generality of that conclusion for a broader region.

In the upper Great Lakes region a dense network of fossil-pollen sites extending across a major vegetational gradient allowed us to investigate several spatial scales of vegetation dynamics simultaneously. In this paper we analyze this network to determine the dominant scales of population variability of three dominant tree taxa (birch, oak, and pine) for 2000-yr intervals from 6500 to $500 \mathrm{yr}$ BP. We use isopoll maps and spatial statistics to assess the degree to which taxa vary in their dominant scale of variation and the degree to which scale-dependent variation has changed through time. Our results have implications for understanding the role of climate as a factor in long-term vegetation dynamics, as well as for modeling efforts that seek to link stand dynamics to large-scale vegetation distributions.

Causal linkages between ecological processes and forcing functions are often inferred from the coincidence of the scale of the response and the forcing. Hierarchy theory provides a formalized basis for this mode of inference by postulating that ecosystems can be decomposed into several functional levels of organization characterized by differences in process rates (Allen and Starr 1982, O'Neill et al. 1986). Interaction can only occur among variables that have similar scales of variation in time and space. Accordingly, explanations of ecological phenomena must identify driving variables that exhibit variance at the same spatial and temporal scales as the phenomena being investigated. By the same reasoning, the relative importance of specific causal processes may change as a function of time and space scales.

Scale-based inference concerning the nature of driving variables responsible for long-term vegetation dynamics has been a cornerstone of Quaternary paleoecology. Explicit specification of scale has added clarity to the long-standing discussion of the relative importance of climate vs. biotic factors in governing Quaternary vegetation change (Prentice 1986, Webb 1986). Mapping of modern pollen data at continental scales demonstrates the role of broad-scale climatic gradients in controlling the distribution of taxa (Webb 1981, Webb et al. 1983a, Bartlein et al. 1986). Similarly, continental-scale maps showing pollen frequencies at 3000-yr intervals over the last $18000 \mathrm{yr}$ appear to represent vegetation responses in dynamic equilibrium to orbitally induced climatic changes (COHMAP 1988, Huntley and Webb 1989, Prentice et al. 1991).

At sufficiently fine temporal and spatial scales (1 ha, 10-100 yr), biotic processes appear to dominate pollen records. Fine-scale networks of pollen data with high spatial and temporal resolution $(100 \mathrm{~km}, 100 \mathrm{yr})$ may show migration lags (Davis et al. 1986), substrate and topographic differentiation (Brubaker 1975, Jacobson 1979, Bernabo 1981, Grimm 1983, Webb et al. 1983b, Gaudreau et al. 1989, Jackson and Whitehead 1991), and the effects of disturbance (Grimm 1983). Climate, as a higher order process, constrains the presence or absence of taxa over broad regions, whereas at finer (regional) scales, vegetation processes exhibit lower order dynamics.

Interpretation of paleovegetation dynamics at intermediate temporal and spatial scales $\left(10^{3} \mathrm{yr} ; 10^{8}\right.$ to $10^{12}$ $\mathrm{m}^{2}$ ) remains controversial (Huntley and Webb 1989). At such scales climatic variance is present but relatively weak compared to longer temporal scales or larger spatial scales (Bernabo 1981, Gajewski 1988), while substrate heterogeneity exerts a relatively stronger influence on vegetation patterning (Brubaker 1975). Successional processes can obscure climatically induced changes in vegetation composition (Davis and Botkin 1985). Delineation of the factors driving paleovegetation dynamics at these scales should be possible where it is possible to define more precisely the dominant scale of variation.

\section{STUdy AREA}

\section{Modern vegetation}

The vegetation patterns that existed at the time of the arrival of Euro-Americans in the 19th century are well known in the upper Great Lakes owing to extensive compilation and analyses of the early Public Land Survey records (Curtis 1959, Kline and Cottam 1979, 


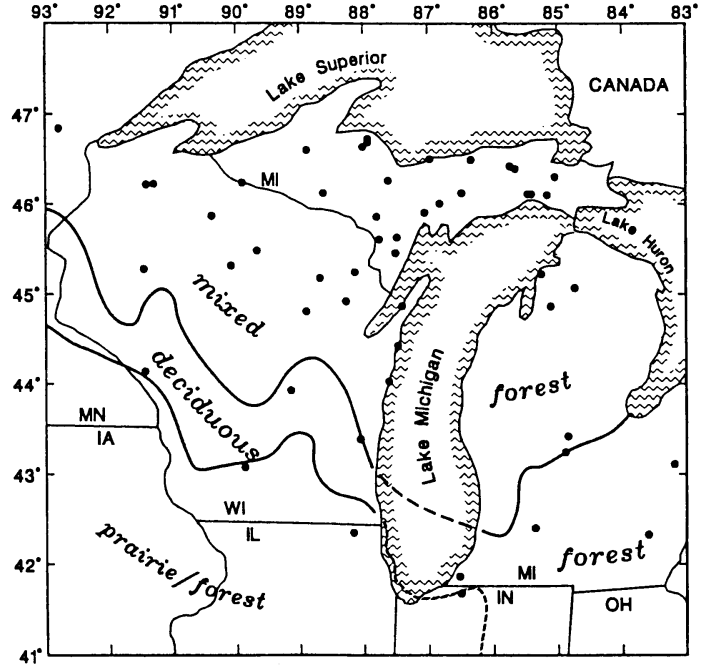

FIG. 1. Map of upper Great Lakes region showing pollen sites and major vegetation zones. State codes: $\mathrm{MN}=\mathrm{Min}$ nesota, $\mathrm{IA}=$ Iowa, $\mathrm{WI}=$ Wisconsin, $\mathrm{IL}=$ Illinois, $\mathrm{MI}=$ Michigan, IN = Indiana, $\mathrm{OH}=$ Ohio.

Whitney 1986). Mixed hardwood-conifer forests covered the majority of the study area (Fig. 1). Important species in these forests included eastern hemlock ( $T s u$ ga canadensis), white pine (Pinus strobus), red pine ( $P$. resinosa), jack pine ( $P$. banksiana), sugar maple (Acer saccharum), yellow birch (Betula lutea), paper birch (B. papyrifera), American beech (Fagus grandifolia), basswood (Tilia americana), and northern red oak (Quercus rubra), An ecotone ("tension zone," Curtis 1959) trending northwest to southeast across the study area separated the mixed forest from the deciduous forest (Fig. 1). Major tree species in the Deciduous forest are bur oak ( $Q$. macrocarpa), black oak ( $Q$. velutina), white oak ( $Q$. alba), American beech, sugar maple, basswood, slippery elm (Ulmus rubra), and black cherry (Prunus serotina). Patterns of species abundance within the broadly defined vegetation types are related to local moisture regime and disturbance frequency, both of which are related in turn to variation in substrate and topography (Curtis 1959, Kline and Cottam 1979, Whitney 1986).

\section{Properties of pollen as vegetation indices}

Relative pollen-taxon abundances, and hence spatial patterns of vegetation as sensed by pollen, depend in part on the different production and dispersal properties of each genus and the pollen-collecting properties of each lake (Jacobson and Bradshaw 1981, Prentice 1985, Jackson 1993). In this study we compare patterns from taxa with roughly similar dispersal properties and productivity (Prentice and Webb 1986); we have avoided analyses of taxa with low productivity or poor dispersal characteristics. Nevertheless, the spatial patterns of vegetation as sensed by pollen data will be systematically different from those sensed by direct vegetation sampling. Our conclusions regarding spatial scales of taxon abundances are therefore interpreted as indicating relative, rather than absolute, scales of variation. Similarly, interpretations of the dimensionality of spatial patterns are made with appropriate recognition of differential pollen dispersal and productivities.

\section{METHODS \\ Pollen data and maps}

Pollen data in a geographical network (Table 1, Fig. 1) were assembled for this study from published and unpublished diagrams from several sources. Pollen diagrams from northern Wisconsin and upper Michigan developed to track the Holocene migration of beech and hemlock form a dense sampling network (Davis et al. 1986, Woods and Davis 1989, Davis et al., unpublished data), Additional diagrams expanding the network into southern Wisconsin and lower Michigan were obtained from the pollen database housed at Brown University (Webb et al. 1983a). Most of the diagrams are from small lakes $(<5 \mathrm{ha})$, with a few moderate-size lakes (5-150 ha) scattered within the sampling network. Both theoretical considerations (Prentice 1985) and empirical evidence (Webb 1974, Prentice 1978, Parsons et al. 1980, Webb et al. 1981, Jackson 1993) indicate that the pollen source-area for such lakes will be dominated by extralocal $(20 \mathrm{~m}$ to 2 $\mathrm{km}$ ) and regional ( 2 to $20 \mathrm{~km}$ ) pollen. The spatial array of pollen data assembled is thus of an appropriate sampling density and scale to characterize regional-scale patterns in abundances of trees (Webb et al. 1978).

Pollen percentages for the three tree genera of interest (birch, oak, and pine) were calculated as a percentage of total terrestrial pollen. Age-depth curves for the enclosing sediments were established by linear interpolation between radiocarbon, corrected radiocarbon, or stratigraphically assigned dates for several levels in each core (Webb et al. 1983a, Woods and Davis 1989).

Pollen percentages for time horizons at 2000-yr intervals from $6500 \mathrm{yr} \mathrm{BP}$ to $500 \mathrm{yr} \mathrm{BP}$ were interpolated from pollen values in samples with estimated ages bracketing a given target year. Extension of the analysis beyond $6500 \mathrm{yr}$ BP was not possible because of the reduced sampling density of sites extending into the early-Holocene (Table 1).

The pollen-percentage data for each time horizon were mapped and contoured using a set of standard numerical procedures designed to produce a constant degree of smoothing both between taxa and between time intervals. Initially the data were interpolated onto a $0.5^{\circ}$ latitude $\times 0.5^{\circ}$ longitude grid, weighting each observation within a defined search radius using a second-degree inverse-distance weighting. We smoothed the resultant grid by averaging adjacent points with a $1^{\circ} \times 1^{\circ}$ center-weighted smoothing matrix. The resultant level of smoothing approximates the spatial scale of regional climatic trends in the study area (Bartlein 
TABLE 1. Characteristics of upper Great Lakes sites for sediment cores.

\begin{tabular}{|c|c|c|c|c|c|c|}
\hline Site name & Lat. & Long. & $\begin{array}{l}\text { Area } \\
\text { (ha) }\end{array}$ & $\begin{array}{l}\text { No. } \\
\text { dates }\end{array}$ & $\begin{array}{l}\text { Oldest } \\
\text { sample } \\
\text { (yr BP) }\end{array}$ & Reference \\
\hline Abraham & $46^{\circ} 22^{\prime}$ & $87^{\circ} 13^{\prime}$ & 3 & 2 & 4147 & Woods and Davis 1989 \\
\hline Ashfork & $46^{\circ} 09^{\prime}$ & $88^{\circ} 08^{\prime}$ & 6 & 2 & 8069 & M. B. Davis, unpublished data \\
\hline Beaver & $44^{\circ} 55^{\prime}$ & $88^{\circ} 09^{\prime}$ & 3.5 & 3 & 5120 & Woods and Davis 1989 \\
\hline Big Bass & $46^{\circ} 10^{\prime}$ & $86^{\circ} 28^{\prime}$ & 6 & ** & 7667 & M. B. Davis, unpublished data \\
\hline Blue Indian & $45^{\circ} 51^{\prime}$ & $87^{\circ} 51^{\prime}$ & 3 & 2 & 5708 & Woods and Davis 1989 \\
\hline Blue Mounds & $43^{\circ} 05^{\prime}$ & $89^{\circ} 52^{\prime}$ & $1^{*}$ & 4 & 10266 & Davis 1977 \\
\hline Bohnes & $44^{\circ} 51^{\prime}$ & $87^{\circ} 19^{\prime}$ & 4 & 2 & 6458 & M. B. Davis, unpublished data \\
\hline Brampton & $45^{\circ} 56^{\prime}$ & $87^{\circ} 1^{\prime}$ & 9.5 & 2 & 7368 & Woods and Davis 1989 \\
\hline Brandt's & $45^{\circ} 38^{\prime}$ & $87^{\circ} 46^{\prime}$ & 5 & 4 & 11288 & Woods and Davis 1989 \\
\hline Buck & $46^{\circ} 32^{\prime}$ & $86^{\circ} 20^{\prime}$ & 1 & 2 & 9150 & M. B. Davis, unpublished data \\
\hline Camp & $46^{\circ} 14^{\prime}$ & $91^{\circ} 20^{\prime}$ & 3.6 & 1 & 8700 & M. B. Davis, unpublished data \\
\hline Camp 11 Lake & $46^{\circ} 40^{\prime}$ & $88^{\circ} 01^{\prime}$ & 1.5 & 11 & 10348 & Brubaker 1975 \\
\hline Capitola & $45^{\circ} 30^{\prime}$ & $89^{\circ} 40^{\prime}$ & 1.7 & 3 & 5630 & M. B. Davis, unpublished data \\
\hline Chippewa & $42^{\circ} 07^{\prime}$ & $83^{\circ} 15^{\prime}$ & $5^{*}$ & 4 & 10024 & Bailey and Ahearn 1981 \\
\hline Clear & $41^{\circ} 40^{\prime}$ & $86^{\circ} 30^{\prime}$ & 20 & 5 & 12493 & Bailey 1972 \\
\hline Crystal Lake & $43^{\circ} 15^{\prime}$ & $84^{\circ} 55^{\prime}$ & $20^{*}$ & 2 & 14633 & R. O. Knapp, unpublished data \\
\hline Disterhaft & $43^{\circ} 55^{\prime}$ & $89^{\circ} 10^{\prime}$ & $5^{*}$ & 6 & 15466 & Baker 1970, Webb and Bryson 1972 \\
\hline E. Soldier & $46^{\circ} 21^{\prime}$ & $84^{\circ} 51^{\prime}$ & 4.8 & 4 & 9650 & Futyma 1982 \\
\hline Frains & $42^{\circ} 20^{\prime}$ & $83^{\circ} 38^{\prime}$ & 6.6 & 9 & 16045 & Kerfoot 1974 \\
\hline Gass & $44^{\circ} 03^{\prime}$ & $87^{\circ} 44^{\prime}$ & 3 & 6 & 14980 & S. Webb 1983 \\
\hline Green & $44^{\circ} 53^{\prime}$ & $85^{\circ} 07^{\prime}$ & 16.2 & 3 & 13965 & Lawrenz 1975 \\
\hline Hemlock & $46^{\circ} 15^{\prime}$ & $91^{\circ} 15^{\prime}$ & 1.5 & 1 & 10862 & Woods and Davis 1989 \\
\hline Hoglund & $45^{\circ} 29^{\prime}$ & $87^{\circ} 29^{\prime}$ & 4 & 3 & 9809 & Woods and Davis 1989 \\
\hline Hudson & $41^{\circ} 40^{\prime}$ & $86^{\circ} 30^{\prime}$ & 175 & 6 & 12216 & Bailey 1972 \\
\hline Hughes & $46^{\circ} 09^{\prime}$ & $86^{\circ} 29^{\prime}$ & 0.25 & 4 & 9454 & K. D. Woods, unpublished data \\
\hline Kellner & $44^{\circ} 15^{\prime}$ & $87^{\circ} 45^{\prime}$ & 6 & 2 & 12236 & Goodwin 1976 \\
\hline Kingburg & $46^{\circ} 32^{\prime}$ & $92^{\circ} 27^{\prime}$ & 9 & 3 & 2304 & Calcote 1986 \\
\hline Kitchner & $45^{\circ} 40^{\prime}$ & $87^{\circ} 27^{\prime}$ & 4 & 4 & 12665 & Woods and Davis 1989 \\
\hline Kroening & $44^{\circ} 48^{\prime}$ & $88^{\circ} 52^{\prime}$ & 4 & 2 & 6568 & Woods and Davis 1989 \\
\hline Lake 27 & $45^{\circ} 04^{\prime}$ & $84^{\circ} 47^{\prime}$ & 45 & 3 & 3263 & Bernabo 1981 \\
\hline Lorraine & $46^{\circ} 09^{\prime}$ & $85^{\circ} 29^{\prime}$ & 5.5 & 2 & 9625 & Woods and Davis 1989 \\
\hline Lost Lake & $46^{\circ} 43^{\prime}$ & $87^{\circ} 58^{\prime}$ & 1 & 8 & 10036 & Brubaker 1975 \\
\hline MacDonald & $46^{\circ} 02^{\prime}$ & $86^{\circ} 48^{\prime}$ & 12 & 4 & 10172 & Woods and Davis 1989 \\
\hline Marion & $45^{\circ} 14^{\prime}$ & $85^{\circ} 15^{\prime}$ & 31 & 3 & 2790 & Bernabo 1981 \\
\hline Mary & $46^{\circ} 15^{\prime}$ & $89^{\circ} 54^{\prime}$ & 1 & 3 & 9744 & Webb 1974 \\
\hline Minerva & $46^{\circ} 09^{\prime}$ & $82^{\circ} 26^{\prime}$ & 18 & 4 & 10390 & M. B. Davis, unpublished data \\
\hline Morrison & $46^{\circ} 10^{\prime}$ & $88^{\circ} 37^{\prime}$ & 3 & 5 & 11625 & Woods and Davis 1989 \\
\hline Penegor & $46^{\circ} 37^{\prime}$ & $88^{\circ} 51^{\prime}$ & 4 & 4 & 9243 & M. B. Davis, unpublished data \\
\hline Radtke & $43^{\circ} 28^{\prime}$ & $88^{\circ} 06^{\prime}$ & 3 & 1 & 11313 & S. Webb 1983 \\
\hline Ryerse & $46^{\circ} 08^{\prime}$ & $85^{\circ} 11^{\prime}$ & 8 & 6 & 8960 & Futyma 1982 \\
\hline Second Bass & $46^{\circ} 41^{\prime}$ & $87^{\circ} 38^{\prime}$ & 7 & 1 & 5564 & M. B. Davis, unpublished data \\
\hline Seidel Lake & $44^{\circ} 27^{\prime}$ & $87^{\circ} 31^{\prime}$ & $<20^{*}$ & 3 & 11450 & $\begin{array}{l}\text { J. C. B. Waddington, } \\
\text { unpublished data }\end{array}$ \\
\hline Spirit & $46^{\circ} 28^{\prime}$ & $86^{\circ} 56^{\prime}$ & 6 & 6 & 12277 & Woods and Davis 1989 \\
\hline Stewart's Dark & $45^{\circ} 18^{\prime}$ & $91^{\circ} 27^{\prime}$ & 7 & & 10932 & Peters and Webb 1979 \\
\hline Tamarack & $46^{\circ} 09^{\prime}$ & $91^{\circ} 27^{\prime}$ & $1^{*}$ & 4 & 4500 & Davis 1979 \\
\hline Vestaberg & $43^{\circ} 25^{\prime}$ & $84^{\circ} 45^{\prime}$ & 1 & 3 & 12671 & Gilliam et al. 1967 \\
\hline Volo Bog & $42^{\circ} 21^{\prime}$ & $88^{\circ} 11^{\prime}$ & $5^{*}$ & 6 & 11116 & King 1981 \\
\hline Wintergreen & $42^{\circ} 25^{\prime}$ & $85^{\circ} 23^{\prime}$ & 14.6 & 10 & 12656 & Manny et al. 1978 \\
\hline Wolverine & $46^{\circ} 26^{\prime}$ & $85^{\circ} 40^{\prime}$ & 3.2 & 5 & 10226 & Futyma 1982 \\
\hline Wood & $45^{\circ} 20^{\prime}$ & $90^{\circ} 20^{\prime}$ & 25.3 & 6 & 13074 & Heide 1981 \\
\hline Yellow Dog & $46^{\circ} 45^{\prime}$ & $87^{\circ} 57^{\prime}$ & 1.5 & 9 & 9175 & Brubaker 1975 \\
\hline Young & $46^{\circ} 27^{\prime}$ & $85^{\circ} 43^{\prime}$ & 2.5 & 3 & 6927 & Woods and Davis 1989 \\
\hline
\end{tabular}

* Approximate values (T. Webb III, personal communication).

** Dated by correlation with Hughes Lake Bog.

et al. 1984, Denton and Barnes 1987). Residuals, which represent the vertical deviation of each data point from the gridded and smoothed pollen-percentage surface at the same location, were calculated and plotted on selected maps.

\section{Numerical analyses}

We used Moran's (1950) I statistic to estimate the strength of spatial autocorrelation as a function of dis- tance between pairs of sites for a given pollen genus and target date. Moran's $I$ statistic is defined by

$$
I=\frac{n \sum_{i} \sum_{j} W_{i j}\left(x_{i}-\bar{x}\right)\left(x_{j}-\bar{x}\right)}{S_{0} \sum_{i}\left(x_{i}-\bar{x}^{2}\right)}
$$

where $n=$ number of samples, $x_{i}=$ the variate value 
at sample $i, \bar{x}=$ mean of $x$ over all locations, $W_{i j}=$ proximity of observations $i$ and $j$, and $S_{0}=\sum_{i} \sum_{j}$

$W_{i j}(i \neq j)$. When there is no autocorrelation present, the expected value of $I$ is $-1 /(n-1)$, when there is maximum positive autocorrelation $I$ will approach 1 , and when there is maximum negative autocorrelation $I$ will approach -1 . Significance levels were calculated using the assumption of randomization: Moran's $I$ is tested against the values that the autocorrelation coefficient could take given all possible permutations of the observed pollen percentages over all localities (Sokal and Oden 1978, Upton and Fingleton 1985).

Cliff and Ord (1973) demonstrate that the most powerful test of the null hypothesis of no spatial autocorrelation against a specified alternative is provided by choosing the $W_{i j}$ values to correspond with the pattern of autocorrelation expected under that alternative. Based on the simple assumption that there is an isotropic decay in the likelihood of similar pollen percentages with distance between sites, we chose to use weights based on the inverse of the Euclidean distance between pairs of sites. Alternative proximity matrices could be constructed to test specific hypotheses of the underlying spatial structure of pollen percentages (e.g., directional gradients, abrupt discontinuities caused by biological barriers) (Sokal and Oden 1978, Legendre and Fortin 1989).

When Moran's $I$ is calculated using the entire network of sites, the statistic reflects the degree to which proximate sites are more similar to each other than they are to more distant sites. Although such a general measure of spatial correlation is informative about the general nature of pollen distribution, the correlation between pairs of sites might be expected to vary in a complex manner with distance, and such spatial patterns are interpretable in terms of underlying processes governing species distributions. To detect such spatial patterns, for each taxon and target year we calculated Moran's $I$ separately for 11 different sets of localities representing 11 mutually exclusive distance classes. The distance classes ranged from $<50 \mathrm{~km}$ to $>500 \mathrm{~km}$, progressing in 50-km increments (i.e., 50 to $100 \mathrm{~km}$, 100 to $150 \mathrm{~km}$, etc.). When Moran's $I$ is plotted as a function of distance classes, the resulting spatial correlogram is analogous to the temporal correlograms used in time-series analysis (Box and Jenkins 1970, Cliff and Ord 1981). As in time-series analysis, interpretation of the correlogram is best accomplished by comparing the observed correlogram with the correlograms to be expected under a variety of theoretical processes. Correlograms can be interpreted ecologically in terms of population patch size and distribution (Sokal 1979, Upton and Fingleton 1985, Legendre and Fortin 1989). In this study short-lag positive autocorrelation would be observed if (1) gradients in taxon abundance exist or (2) the patch size of homogeneous vegetation units has a diameter that exceeds the smallest inter-point sampling distance. Autocorrelation that falls to non-significant values at medium and long lags is analogous to a low-order autoregressive model in time-series analysis. In the context of our study, the lag or distance at which autocorrelation falls to zero can be interpreted as the average patch size. Short-lag negative autocorrelation could result from a heterogeneous mosaic of vegetation patches of smaller average diameter than the inter-site distance. Long-lag positive autocorrelation would be a consequence of a patch size that is much larger than the inter-site distance and a patch arrangement that exhibits a regularity across the landscape (e.g., vegetation differentiation within regularly spaced ridge and valley topography or a circular cline in a taxon distribution with a radius approximately equal to the longest inter-site distances). Long-lag negative autocorrelation would be indicative of a cline or gradient in taxon abundance. Autocorrelation will be non-significant at all distances when a taxon is randomly arrayed across the landscape.

\section{RESULTS}

The maps depicting smoothed isopolls and associated residuals (Figs. 2-4) indicate that each tree genus varies in the degree to which its spatial patterns can be described by large-scale gradients. The gradient in oak pollen percentages at 500 yr BP reflects the changing importance of oak on the landscape as one moves from the deciduous forest in the south to the mixed forest in the north (Fig. 2a) and, as such, is similar to results published elsewhere (Webb et al. 1983a). The residuals, representing the deviation of oak pollen percentages from estimated values at individual sites, show a high degree of spatial coherence. Negative residuals, shown as darkened circles, are almost entirely restricted to the northernmost sector of the study area while positive residuals, shown as clear circles, are segregated in the south. The estimated values of oak pollen thus are slightly and systematically biased; a contouring scheme of roughly the same configuration but allowing for steeper gradients would have provided a better regional fit to the observed data. Not surprisingly, several large residuals are located near the ecotone between the deciduous and mixed conifer forest. Otherwise no evidence exists for finer scale spatial patterning of oak pollen abundances at this time horizon. The pattern of

FIG. 2. Maps showing smoothed pollen-frequency isolines (5\% contour intervals) and associated residuals for (a) oak, (b) pine, and (c) birch at 2000-yr intervals through the late-Holocene. The residuals (i.e., the difference between observed pollen percentages and estimated values at individual sites) are shown by open circles for positive residuals and solid circles for negative residuals. The size of the symbol represents the relative size of residual and is scaled proportionally between the minimum and maximum residual value for each map. 
Oak: 0.5 kyr BP

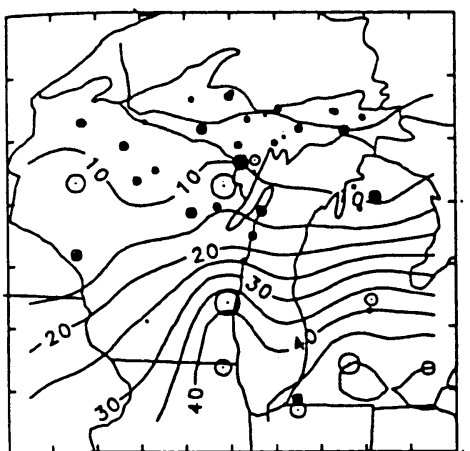

Oak: 2.5 kyr BP

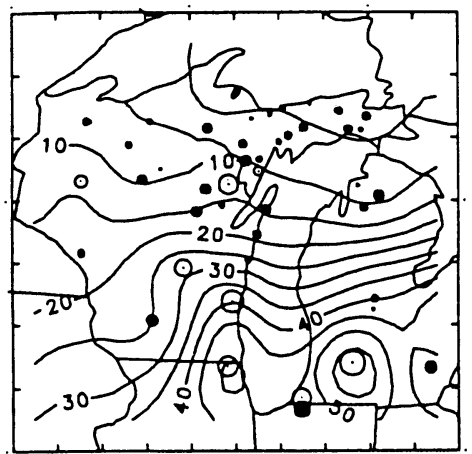

Oak: $4.5 \mathrm{kyr} B P$

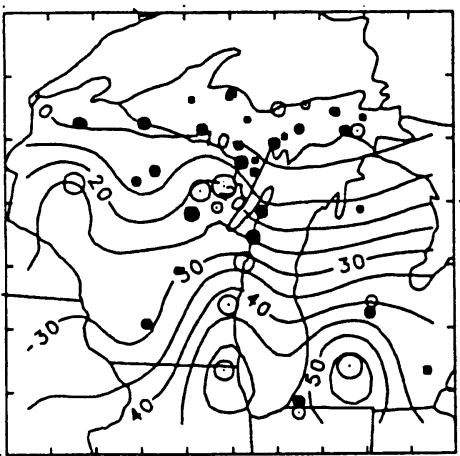

Oak: 6.5 kyr BP

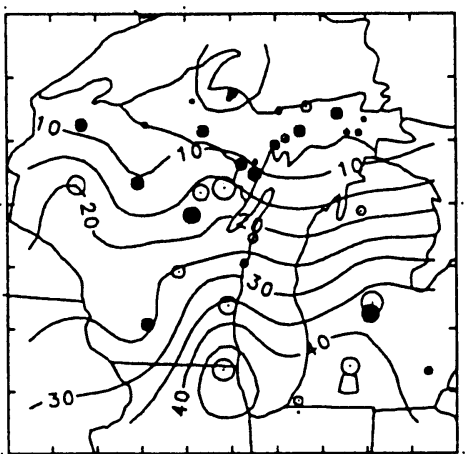

Pine: 0.5 kyr BP

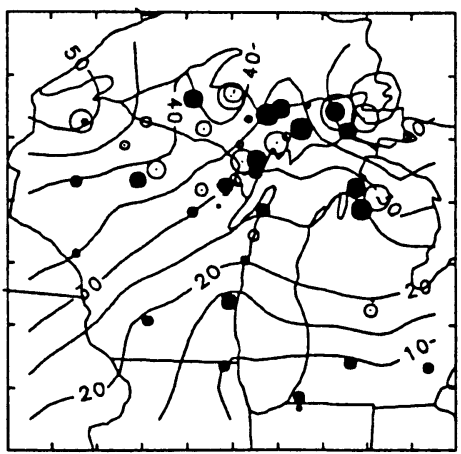

Pine: 2.5 kyr BP

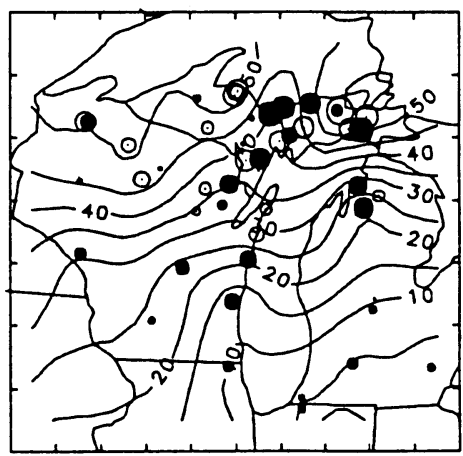

Pine: $4.5 \mathrm{kyr} B P$

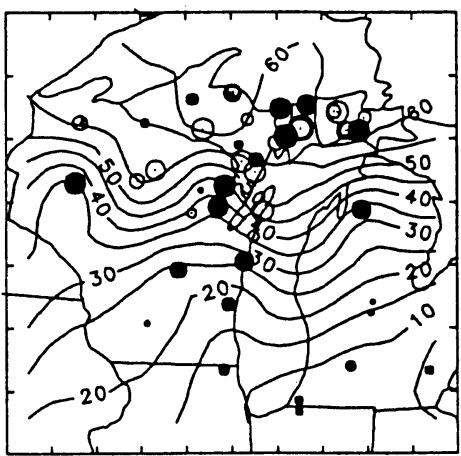

Pine: 6.5 kyr BP

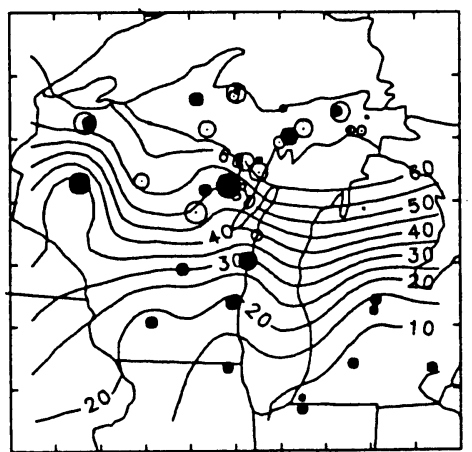

Birch: 0.5 kyr BP

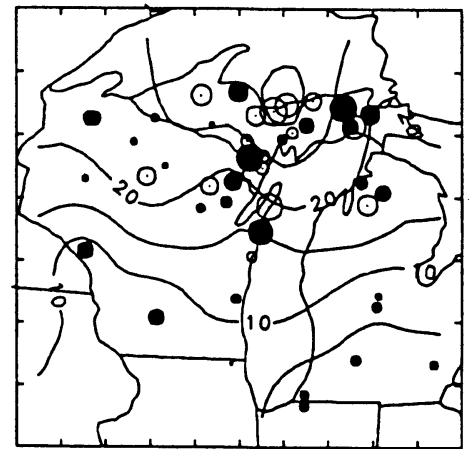

Birch: 2.5 kyr BP

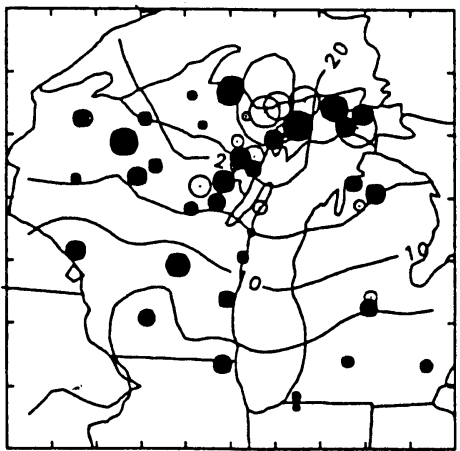

Birch: 4.5 kyr BP

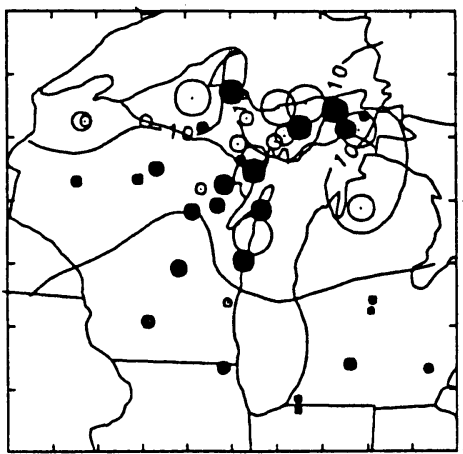

Birch: 6.5 kyr BP

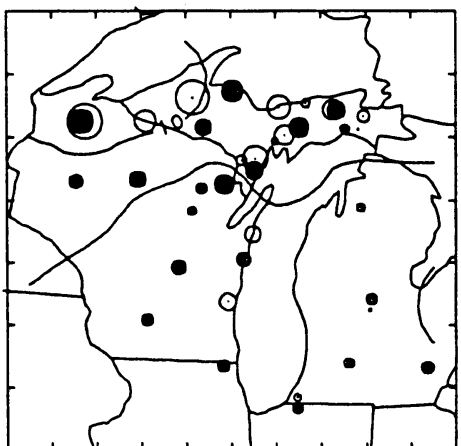




\section{a. oak}

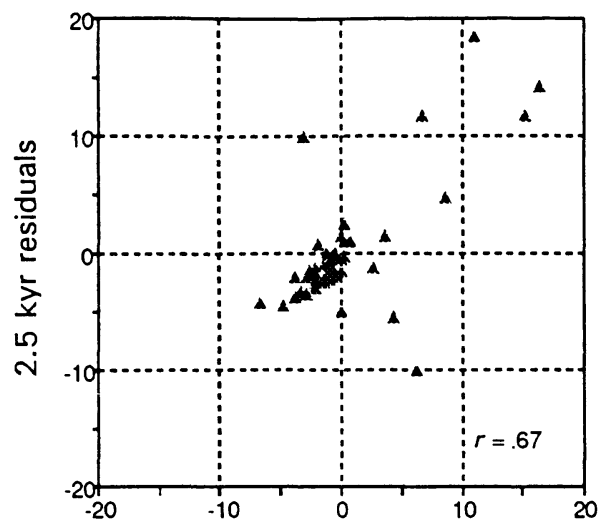

b. birch

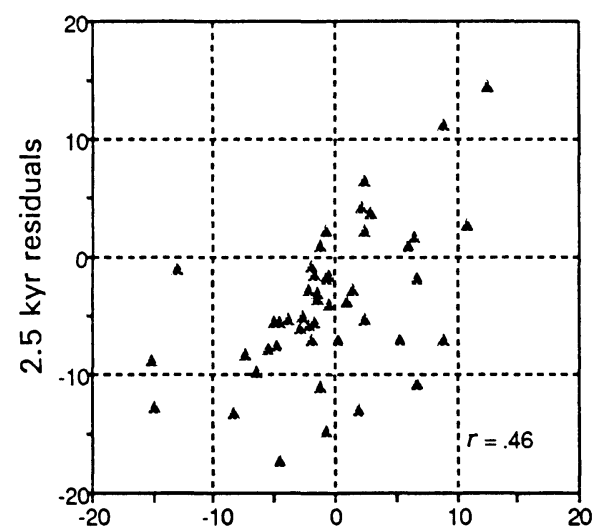

c. pine

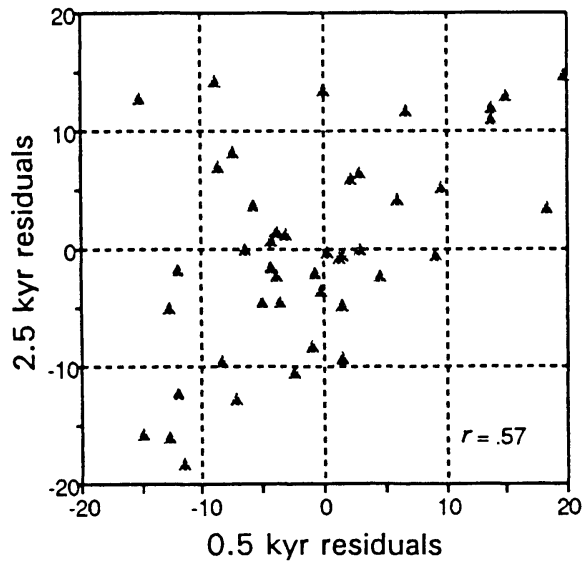

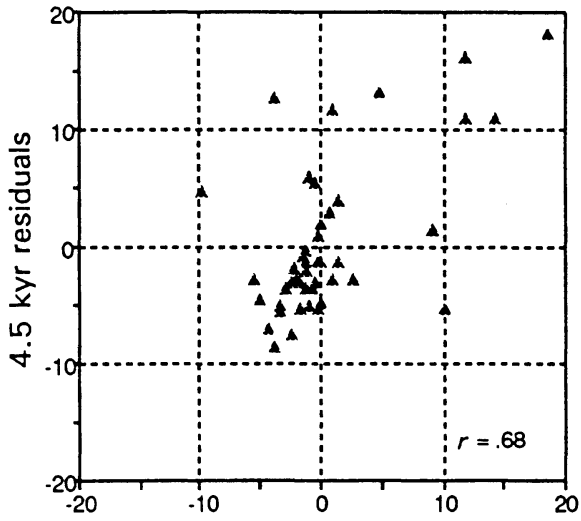
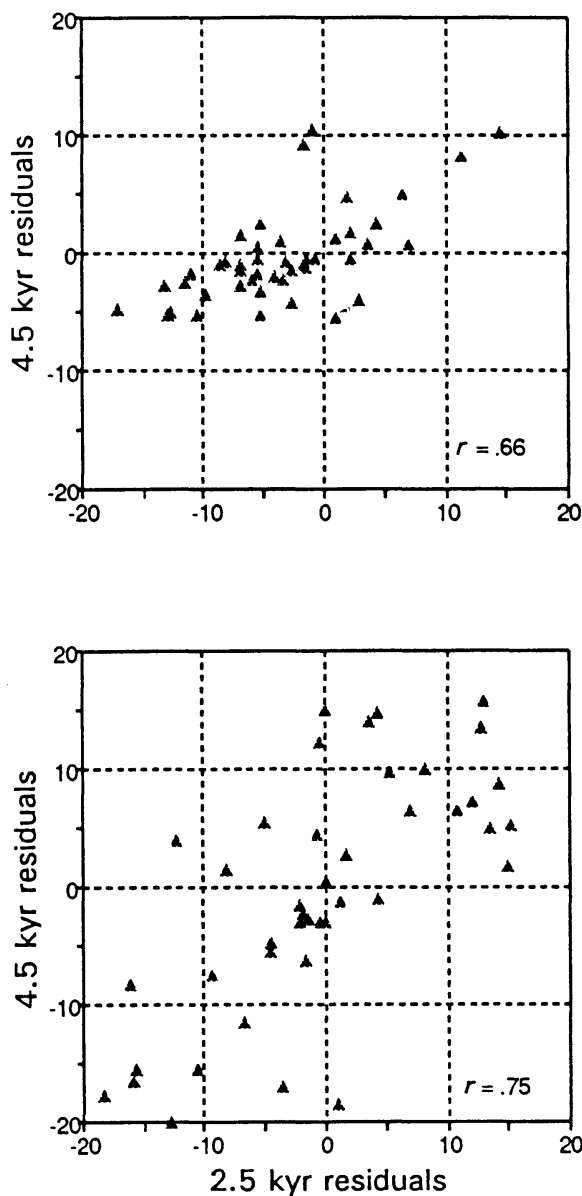

FIG. 3. Scatter plots of residuals from smoothed pollen maps shown in Fig. 2 plotted for paired, consecutive 2000-yr intervals for (a) oak, (b) birch, and (c) pine. Pearson product-moment correlations $(r)$ are shown on each plot. All correlations are significant at $P<.05$.

oak abundance changed subtly over the mid- to lateHolocene with a small southward shift of isopolls between 6500 and $2500 \mathrm{yr}$ BP. The size and pattern of the residuals remained essentially the same.

At 500 yr BP pine pollen exhibits a gradient opposite to that of oak pollen, with highest values in the mixed conifer forest of the north and lowest values in the deciduous forest of the south (Fig. 2b). Unlike oak, pine pollen percentages exhibit fine-scale variability: the residuals, especially in the north, are large and high- 

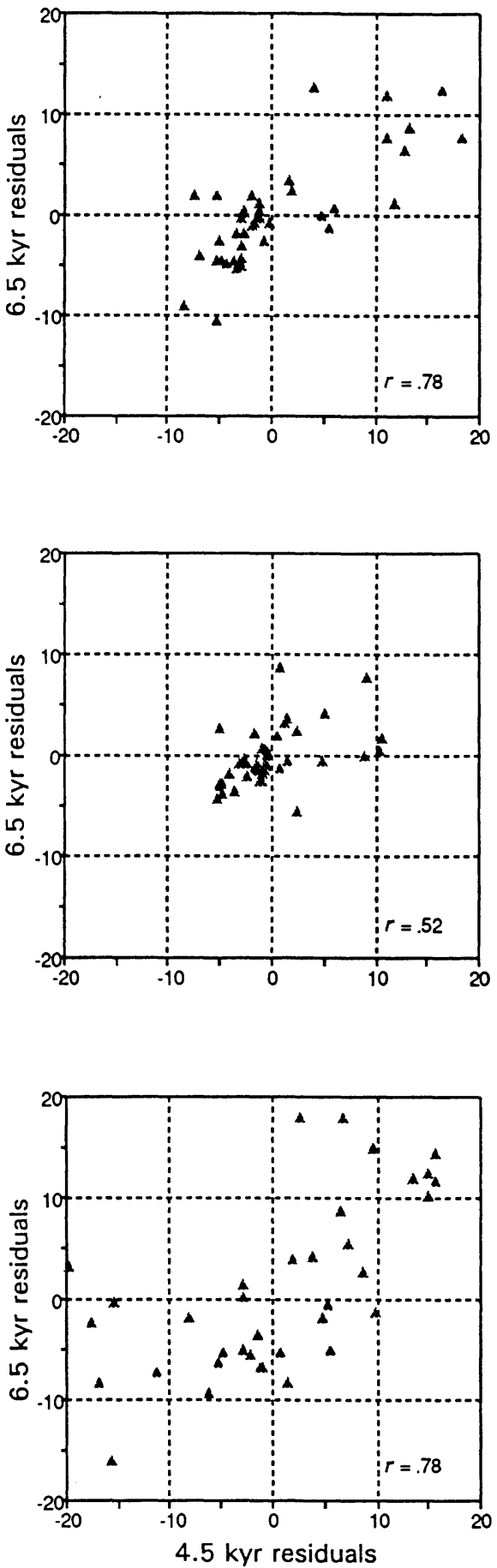

FIG. 3. Continued.

ly variable in sign and magnitude. Similar fine-scale variability superimposed on a broad gradient in abundance occurred at other time intervals (Fig. 2b). The gradient in birch abundance was less steep than oak or pine (Fig. 2c). Like pine, the high variability in birch abundance from site to site is manifest in large residual values.

Scatterplots of residuals for one time interval plotted against those for the preceding time interval allow us to monitor the frequency with which residuals change sign or magnitude between time intervals (Fig. 3). If residuals are relatively similar between time intervals, then the residual variation seen in the pollen maps is likely to be related to site characteristics. If, on the other hand, residuals show little correlation between time intervals, the source of residual variation is a process that operates randomly over the landscape. The plots and associated correlation coefficients indicate that in general residuals are highly correlated from one time interval to the next. Exceptions to this generalization occur between 500 and 2500 yr BP when the plots and associated correlation coefficients for pine and birch indicate a weakening in the relationship between residuals at successive time periods. For birch, many residuals change sign from negative to positive between 2500 and $500 \mathrm{yr} \mathrm{BP}$, while for pine, there is a trend for positive residuals to become negative over the same time interval.

Spatial correlograms allow a more formal characterization of the dominant scales of variation as depicted in the isopoll and residual maps. The spatial correlograms for 500 yr BP represent the spatial organization of each pollen taxon as it would have been observed in the landscape just prior to European settlement (Fig. 4). Oak pollen exhibits the highest absolute magnitude of both short-distance and long-distance autocorrelation. The pattern of slowly decaying values of Moran's $I$ as distances increase resembles correlograms of temporal (positive) autoregressive processes, implying that the most important factors governing oak abundance vary along gradients equalling or exceeding the scale of the study area. At $500 \mathrm{yr}$ BP birch pollen has lower absolute autocorrelation values at all distances and the significant positive autocorrelation damps out at shorter distances than oak, implying that, compared to oak, factors operating at broad spatial scales are less important in governing spatial distribution of birch pollen. Birch pollen abundances remain positively associated at finer scales than those for oak ( $\approx 150 \mathrm{~km}$ for birch vs. $300 \mathrm{~km}$ for oak). Similarly, Moran's $I$ values for pine pollen are also lower in absolute value than those for oak, indicating lesser importance of large-scale controls for pine. Although pine populations exhibit a significant level of positive autocorrelation for distances up to $200 \mathrm{~km}$, the strength of positive association falls off dramatically after 50 $\mathrm{km}$.

The relative temporal stability of these scales of spatial variability can be examined by comparing spatial correlograms for each of the four time intervals. The spatial structure of oak pollen abundances was stable through time (Fig. 5a). Small variations in the magnitude of Moran's $I$ for oak occurred at short distances, 


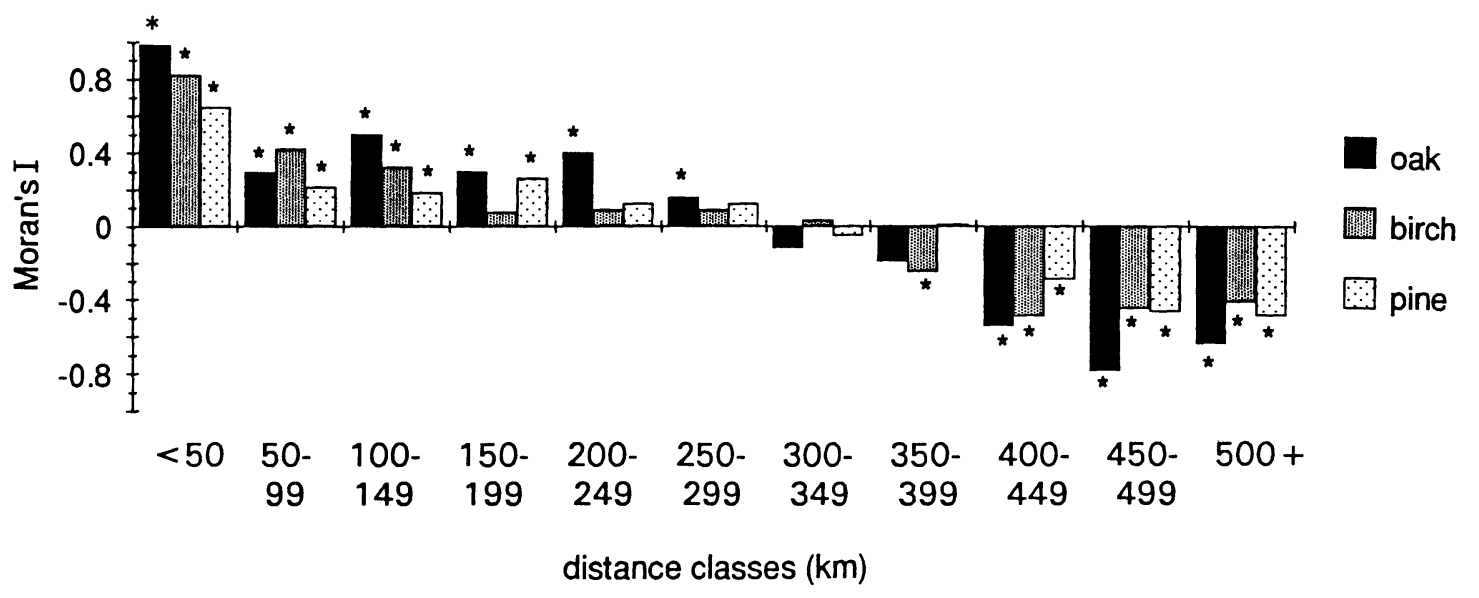

FIG. 4. Spatial autocorrelation of oak, birch, and pine at $500 \mathrm{yr}$ BP, as measured by Moran's $I$ statistic, for varying separation distances between sites. Values significant at $P<.05$ are indicated with an asterisk.

but the general features of the correlogram (i.e., distance at which positive autocorrelation approaches zero and relative magnitude of negative autocorrelation at long distances) were stable over the four time intervals.

This stability is in marked contrast to the changing structure of the correlogram for birch (Fig. 5b). The significantly high autocorrelation at short lags seen at $500 \mathrm{yr}$ BP for birch is not visible in antecedent time intervals (i.e., no significantly positive short-distance autocorrelation at $4500 \mathrm{yr}$ BP and $6500 \mathrm{yr}$ BP). Similarly, the absolute value of negative autocorrelation diminished at long distances, and the distance at which negative values were significant increased, implying an overall lessening in the past of the importance of broadscale gradients in controlling birch abundance. At 4500 and $6500 \mathrm{yr}$ BP the correlogram for birch indicated that birch populations were, for the most part, randomly distributed on the landscape, with a low but significant trend towards negative association at very large $(>450 \mathrm{~km})$ distances.

The spatial structure of pine abundances showed a similar instability, but with a trend towards increasing levels of spatial autocorrelation farther back in time (Fig. 5c). The increasing magnitude of short-distance positive and long-distance negative autocorrelation from 500 to $6500 \mathrm{yr}$ BP implies that broad-scale gradients were more important in the past in controlling pine abundances than they were at the time of settlement. At $6500 \mathrm{yr}$ BP the spatial structure of pine populations was very similar to oak, dominated by largescale variability.

The rate of change in spatial structure as observed in the correlograms for birch and pine was not constant through time. The largest change in both long- and short-distance autocorrelation for both species occurred between 500 and $2500 \mathrm{yr}$ BP. This time interval was also associated with changes in the sign of the residuals for birch and pine at a number of the sites, and a decline in the correlation of residuals between successive time periods (Fig. 3).

\section{Discussion AND CONCLUSIONS}

\section{Sources of fine-scale variability in pollen data}

Interpretation of the changing importance of finescale variability among birch, pine, and oak through time requires disentangling the sources of fine-scale variability in pollen data. These sources include the sampling properties of the pollen record as well as scaling factors associated with environmental heterogeneity. Processes operating over relatively short time scales, such as successional responses to disturbance, are important for explaining fine-scale patterning of vegetation on the modern landscape but are less useful as explanations for pollen-based vegetation reconstructions. Most pollen samples from lake sediments integrate pollen deposition over 5 to $>50 \mathrm{yr}$ and thus integrate vegetation over temporal scales equivalent to those of successional processes (Webb 1987).

Differential pollen production, dispersal, and sampling properties of lake basins could, by themselves, cause differences in spatial autocorrelation patterns. Highly productive, wind-pollinated species with light pollen grains are overrepresented in pollen samples (Prentice and Webb 1986, Jackson 1993), causing a higher degree of spatial autocorrelation than actually exists in the trees on the landscape because such grains occur in abundance outside the stands in which the source trees occur. Alternatively, insect-pollinated species with heavy pollen grains are poorly represented in pollen samples, and thus exhibit less spatial autocorrelation in the pollen record than the corresponding trees exhibit on the landscape. By focusing our study on three genera of relatively similar pollen dispersal properties, we have minimized these systematic errors in our estimates of variation among genera in spatial autocorrelation. In fact, our results indicate that the bias in autocorrelation estimates that would be expected due to variation in dispersal properties among the three taxa appears to be minimal. For small to moderate lakes in the mixed conifer forest, theoretical 

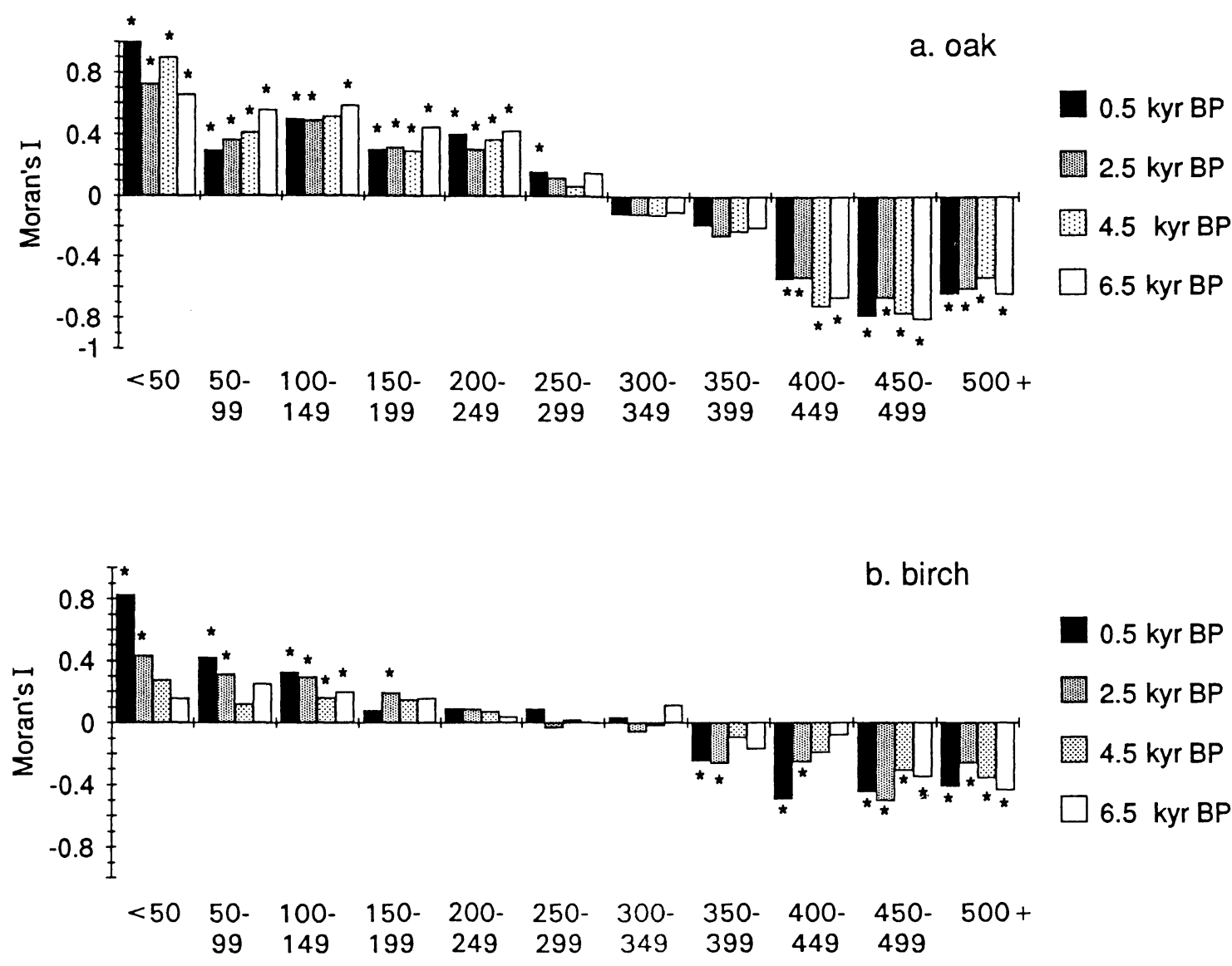

$0.5 \mathrm{kyr} \mathrm{BP}$

$2.5 \mathrm{kyr} B P$

$4.5 \mathrm{kyr} \mathrm{BP}$

$6.5 \mathrm{kyr} \mathrm{BP}$

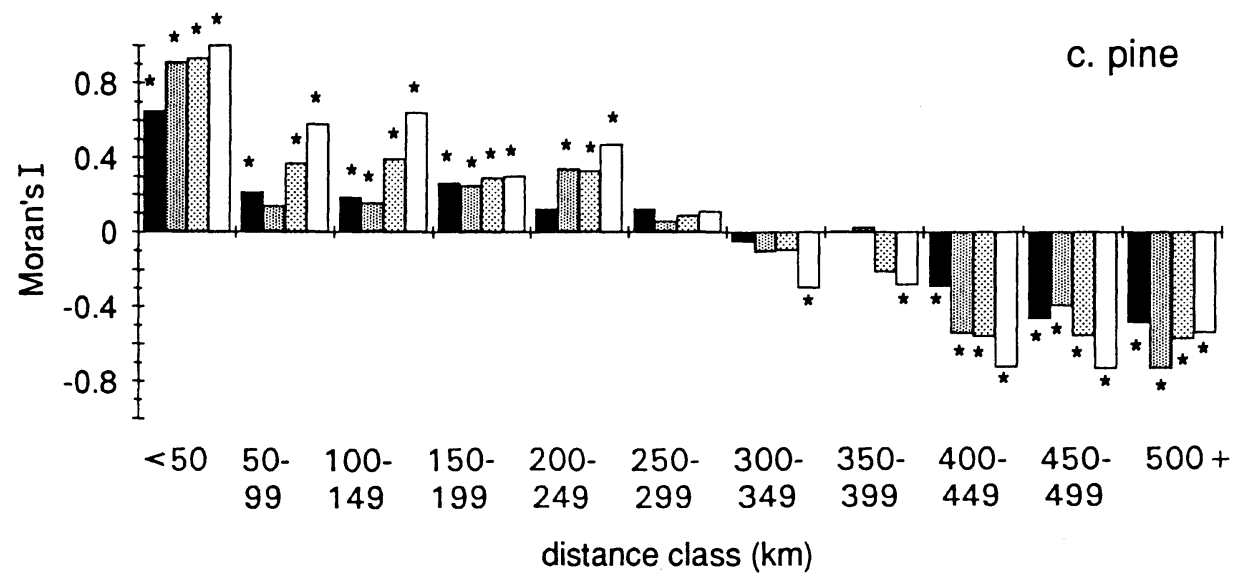

0.5 kyr BP

$2.5 \mathrm{kyr} B P$

$4.5 \mathrm{kyr} \mathrm{BP}$

$6.5 \mathrm{kyr} \mathrm{BP}$

Fig. 5. Temporal variation in spatial autocorrelation of (a) oak, (b) birch, and (c) pine. Values significant at $P<.05$ are indicated with an asterisk.

and empirical results indicate that the pollen sourceareas for pine and birch (and hence the degree of positive spatial autocorrelation) should be larger than that for oak (Prentice 1985, Prentice and Webb 1986). Contrary to these predictions, we find that the presettlement pollen data indicate that oak exhibits the highest level of short-distance spatial autocorrelation, followed by birch and then pine (Fig. 4).
An alternative explanation of the observed pattern of high autocorrelation in oak is its high pollen productivity as compared to other tree taxa in the southern forests. Due to the low pollen productivity of the other dominants of the southern forests (i.e., maple, basswood, beech), patchiness within the southern forests might go undetected by spatial statistics. We tested this idea as an alternative explanation for the high spatial 
autocorrelation exhibited by oak by deleting all sites located in deciduous forest and prairie forest vegetation (Fig. 1). These were no significant differences between the autocorrelation estimates of the full vs. the reduced data sets. Taken together, these results imply that the processes related to pollen dispersal and productivity introduce negligible systematic bias into our estimates of the relative spatial scaling of taxon abundances.

The nature of the pollen-sampling network also influences estimates of spatial structure. The density of samples (i.e., "resolution," Prentice 1986 or "grain," Allen and Starr 1982) imposes a lower limit to the detection of autocorrelation. The definition of the boundaries and size of the study region (i.e., "frame," Prentice 1986) will influence the relative importance of different sources of spatial variability in the pollen data (Bartlein et al. 1986). At the continental scale, strong gradients in species abundance related to macroclimate outweigh the variation between samples that derives from finer-scale variation in topography and soils (Solomon and Webb 1985). When the spatial frame contracts and the sampling density becomes correspondingly finer, the relative variation in pollen abundance due to local factors increases (Solomon and Webb 1985). The frame size and sampling density employed here was purposely chosen to straddle scales of variation: the study region is of sufficient size to extend across a climatically controlled gradient in forest composition $(\approx 500 \mathrm{~km})$ while samples are of sufficient density to detect finer-scale patterns in forest composition owing to edaphic or disturbance mosaics at scales from 50 to $250 \mathrm{~km}$.

Environmental controls of forest growth operate along a spectrum of scales (Jarvis and McNaughton 1986) and constitute another source of variability in pollen data. The isopoll and residual maps, together with the spatial correlograms, indicate that genera differ substantially in the importance of fine-scale variability, and that for both pine and birch short- $(<50 \mathrm{~km})$ to medium-scale (100-200 km) variation is as important as broad-scale gradients in governing abundance. Two aspects of the mapped patterns and scaling parameters indicated by the correlograms suggest that substrate is an important factor controlling the spatial structure of taxon abundance. First, the constancy of sign and magnitude of residual variation from time interval to time interval (Fig. 3) suggest that the variation unexplained by the isopoll maps does not vary randomly between time intervals. Site-specific factors are thus responsible for the residual variation from the smoothed isopolls. Second, glacial deposits and associated soil associations show variability with dimensions approximating 20-150 km (Hole 1976, Farrand 1982). Maps of vegetation prior to European settlement (Finley 1976) show a similar scale of variation characterizing major forest types and further indicate that major forest types are strongly correlated with mapped soil associations. The ability of substrate to impose pattern on vegetation is related to a wide range of factors, some of which directly affect forest growth and regeneration (e.g., soil nutrients, water-holding capacity) and some of which indirectly affect microclimate or frequency of fire (e.g., soil texture, topographic features).

\section{Changing spatial scales of taxon abundances during the Holocene}

Previous descriptions of Holocene vegetation change in the upper Great Lakes emphasized changes in the abundance of major taxa as indicated by movement of isopolls and range limits (Webb et al. 1983a, Davis et al. 1986). A conclusion of these and other paleoecological studies (Davis 1976, 1981, Webb 1981, Jacobson et al. 1987) is that tree species behave individualistically with respect to environmental constraints and, as a result, they occur in changing associations through time. Our results indicate that the spatial pattern of population distributions on the landscape (as recorded by pollen data) is highly individualistic as well. Some genera (e.g., oak) are strongly positively spatially autoregressive; other genera (e.g., pine at 500 yr BP) are more patchy in distribution; and still others (e.g., birch at $6500 \mathrm{yr}$ BP) are essentially random in their spatial structure. Further, we find that genera alter this spatial structure under conditions of climatically induced population expansion or contraction. Relatively small decreases in pine percentages from midHolocene to pre-settlement times are associated with a trend towards decreasing positive association between pine populations at short to medium distances (decreasing patchiness). Similarly, small increases in birch percentages over the same time interval are associated with increases in autocorrelation over short to medium distances (increasing patchiness).

An explanation for these patterns lies in a generalization of Brubaker's (1975) observation that vegetation response to climate change varies with substrate types, resulting in mosaics of forest types with different scaling properties through time. We postulate that the observed changes in spatial structure result from expansions or contractions of tree populations on soils derived from materials intermediate in texture coarse outwash and fine till. Under warm, dry, mid-Holocene climatic conditions, pine (largely white pine) expanded on these intermediate substrates. As conditions became cooler and wetter, elements of the mesic, deciduous forest increased at the expense of the white pine populations on these substrates, resulting in the greater spatial coherence observed in the birch populations. Changes in the relative importance of ecologically distinct species of birch is a further means by which spatial structure of a genus might change through time. During the early- to mid-Holocene, macrofossil evidence indicates that paper birch, the birch species favored by disturbance, was more abundant in the mixed forest of the upper Great Lakes than yellow birch, the more mesic congener (Webb 1988). The increasing spatial 
coherence of birch pollen from mid-Holocene to presettlement times probably reflects that increasing dominance of yellow birch over paper birch in the pollen record. Spatial statistics, by indicating the dominant scales of variation, thus point to hypotheses that can be directly tested using sampling schemes explicitly scaled to account for the observed variance.

An implication of these results is that the pre-settlement vegetation represents only one of a number of previously realized spatial organizations of tree populations. Spatial patterns of pre-settlement vegetation are commonly looked to as a source of information on vegetation processes (Kline and Cottam 1979, Grimm 1984, Whitney 1986) or as a standard against which to measure human impact (Sharpe et al. 1987). Our results indicate that spatial organization is dynamic, changing in response to long-term climatic change. Finescale vegetation patterning is a more or less important feature depending on the degree to which climate influences the sensitivity of a species or genus to substrate differences. In other words, the degree of constraint of the higher order process (i.e., climate) varies with time and is individualistic with respect to each taxon. The ability of large-scale macroclimatic patterns to explain the distribution of trees thus not only varies with the resolution and spatial extent of the study area (Prentice 1986), but also varies among taxa and, for a single taxon, between time intervals representing different climatic regimes.

\section{ACKNOWLEDGMENTS}

We thank Richard Futyma, Randy Calcote, Jim LebensMack, and Kerry Woods for permission to use unpublished pollen data. Tom Webb provided data from the Brown University pollen database. Comments by Pat Bartlein, Steve Jackson, George Jacobson, Paul Sheppard, Tom Stohlgren, Shinya Sugita, Tom Webb, and two anonymous reviewers improved the manuscript. This research was supported by NSF Grant SES89-42873 to L. J. Graumlich.

\section{Literature Cited}

Allen, T. F. H., and T. B. Starr. 1982. Hierarchy. Perspectives for ecological complexity. The University of Chicago Press, Chicago, Illinois, USA.

Bailey, R. E. 1972. Pollen stratigraphy of Wintergreen Lake. Page 24 in R. O. Kapp, editor. Handbook for paleoecology field trip in central lower Michigan. Ecological Society of America, Lansing, Michigan, USA.

Bailey, R. E., and P. J. Ahearn. 1981. A late and postglacial pollen record from Chippewa Bog, Lapeer Co., MI: further examination of white pine and beech immigration into the central Great Lakes region. Pages 53-74 in R. C. Romans, editor. Geobotany II. Plenum, New York, New York, USA.

Baker, R. G. 1970. A radiocarbon-dated pollen chronology for Wisconsin: Disterhaft Farm Bog revisited. Geological Society of America Abstracts 2:488.

Bartlein, P. J., I. C. Prentice, and T. Webb III. 1986. Climatic response surfaces from pollen data for some eastern North American taxa. Journal of Biogeography 13:35-57.

Bartlein, P. J., T. Webb III, and E. Fleri. 1984. Holocene climatic change in the northern Midwest: pollen-derived estimates. Quaternary Research 22:361-374.

Bernabo, J. C. 1981. Quantitative estimates of temperature changes over the last 2700 years in Michigan based on pollen diagrams. Quaternary Research 15:143-159.

Bernabo, J. C., and T. Webb III. 1977. Changing patterns in the Holocene pollen record of northeastern North America: a mapped summary. Quaternary Research 8:64-96.

Box, G. E. P., and G. M. Jenkins. 1970. Time series analysis: forecasting and control. Holden-Day, San Francisco, California, USA.

Brubaker, L. B. 1975. Post-glacial forest patterns associated with till and outwash in northcentral Upper Michigan. Quaternary Research 5:499-527.

Calcote, R. R. 1986. Hemlock in Minnesota: 1200 years as a rare species. Thesis. University of Minnesota, Minneapolis, Minnesota, USA.

Cliff, A. D., and J. K. Ord. 1973. Spatial autocorrelation. Pion, London, England.

Cliff, A. D., and J. K. Ord. 1981. Spatial processes, models and applications. Pion, London, England.

COHMAP [Cooperative Holocene Mapping Project]. 1988. Climatic changes of the last 18,000 years: observations and model simulations. Science 241:1043-1051.

Curtis, J. T. 1959. The vegetation of Wisconsin. University of Wisconsin Press, Madison, Wisconsin, USA.

Davis, A. M. 1977. The prairie-deciduous forest ecotone in the upper Middle West. Annals, Association of American Geographers 67:204-213.

1979. Wetland succession, fire, and the pollen record: a Midwestern example. American Midland Naturalist 102:86-94.

Davis, M. B. 1976. Pleistocene biogeography of temperate deciduous forests. Geoscience and Man 13:13-26.

. 1981. Quaternary history and the stability of deciduous forests. Pages 132-153 in D. C. West, H. H. Shugart, and D. B. Botkin, editors. Forest succession: concepts and applications. Springer-Verlag, New York, New York, USA.

Davis, M. B., and D. B. Botkin. 1985. Sensitivity of cooltemperate forests and their fossil pollen record to rapid temperature change. Quaternary Research 23:327-340.

Davis, M. B., K. D. Woods, S. L. Webb, and R. P. Futyma. 1986. Dispersal versus climate: expansion of Fagus and Tsuga into the upper Great Lakes region. Vegetatio 67:93103.

Denton, S. R., and B. V. Barnes. 1987. Spatial distribution of ecologically applicable climatic statistics in Michigan. Canadian Journal of Forest Research 17:598-612.

Farrand, W. R. 1982. Quaternary geology of Michigan. Geological Survey, Department of Natural Resources, State of Michigan, Lansing, Michigan, USA.

Finley, R. W. 1976. Original vegetation cover of Wisconsin from U.S. General land Office Notes (map). U.S. Forest Service, North Central Forest Experiment Station, Saint Paul, Minnesota, USA.

Futyma, R. P. 1982. Postglacial vegetation of eastern Upper Michigan. Dissertation. University of Michigan, Ann Arbor, Michigan, USA.

Gajewski, K. 1988. Late Holocene climate changes in eastern North America estimated from pollen data. Quaternary Research 29:255-262.

Gaudreau, D. C., S. T. Jackson, and T. Webb, III. 1989. Spatial scale and sampling strategy in paleoecological studies of vegetation patterns in mountainous terrain. Acta Botanica Neerlandica 38:369-390.

Gilliam, J. A., R. O. Kapp, and R. D. Bogue. 1967. A postWisconsin pollen sequence from Vestaburg Bog, Montcalm County, Michigan. Michigan Academy of Sciences, Arts, and Letters 52:3-17.

Goodwin, R. G. 1976. Vegetation response to the Two Rivers advance based on a pollen diagram from Kellners Lake, Manitowoc County, Wisconsin. Thesis. Geology and Geo- 
physics, University of Wisconsin, Madison, Wisconsin, USA.

Grimm, E. C. 1983. Chronology and dynamics of vegetation change in the prairie-woodland region of southern Minnesota, U.S.A. New Phytologist 93:311-350.

- 1984. Fire and other factors controlling the Big Woods vegetation of Minnesota in the mid-nineteenth century. Ecological Monographs 54:291-311.

Heide, K. M. 1981. Late-Quaternary vegetational history of north-central Wisconsin, USA: estimating forest composition from pollen data. Dissertation. Brown University, Providence, Rhode Island, USA.

Hole, F. D. 1976. Soils of Wisconsin. University of Wisconsin Press, Madison, Wisconsin, USA.

Huntley, B., and T. Webb III. 1989. Migration: species' response to climatic variation caused by changes in the earth's orbit. Journal of Biogeography 16:5-19.

Jackson, S. T. 1993. Pollen and spores in Quaternary lake sediments as sensors of vegetation composition: theoretical models and empirical evidence. In A. Traverse, editor, Sedimentation of organic particles. Cambridge University Press, Cambridge, England, in press.

Jackson, S. T., and D. R. Whitehead. 1991. Holocene vegetation patterns in the Adirondack Mountains. Ecology 72: 641-653.

Jacobson, G. L., Jr. 1979. The palaeoecology of white pine (Pinus strobus) in Minnesota. Journal of Ecology 67:697726.

Jacobson, G. L., Jr., and R. H. W. Bradshaw. 1981. The selection of sites for paleovegetational studies. Quaternary Research 16:80-96.

Jacobson, G. L., Jr., T. Webb III, and E. C. Grimm. 1987. Patterns and rates of vegetation change during the deglaciation of eastern North America. Pages 277-288 in W. F. Ruddiman and H. E. Wright, Jr., editors. North America and adjacent oceans during the last deglaciation. Geological Society of America, Boulder, Colorado, USA.

Jarvis, P. G., and K. G. McNaughton. 1986. Stomatal control of transpiration: scaling up from leaf to region. Advances in Ecological Research 15:1-49.

Kerfoot, W. C. 1974. Net accumulation rates and the history of cladoceran communities. Ecology 55:51-61.

King, J. E. 1981. Late Quaternary vegetational history of Illinois. Ecological Monographs 55:51-61.

Kline, V. M., and G. Cottam. 1979. Vegetation response to climate and fire in the Driftless Area of Wisconsin. Ecology 60:861-868.

Lawrenz, R. W. 1975. The developmental paleoecology of Green Lake, Antrim County, Michigan. Thesis. Central Michigan University, Mount Pleasant, Michigan, USA.

Legendre, P., and M.-J. Fortin. 1989. Spatial pattern and ecological analysis. Vegetatio 80:107-138.

Manny, B. A., R. G. Wetzel, and R. E. Bailey. 1978. Paleolimnological sedimentation of organic carbon, nitrogen, phosphorous, fossil pigments, pollen, and diatoms in a hypereutrophic lake: a case history of eutrophication. Polskie Archiwum Hydrobiologii 25:243-267.

Miller, N. G., and R. P. Futyma. 1987. Paleohydrological implications of Holocene peatland development in northern Michigan. Quaternary Research 27:243-267.

Moran, P. A. P. 1950. Notes on continuous stochastic phenomena. Biometrika 37:17-23.

O'Neil, R. V., D. L. DeAngelis, J. B. Wade, and T. F. H. Allen. 1986. A hierarchical concept of ecosystems. Princeton University Press, Princeton, New Jersey, USA.

Parsons, R. W., I. C. Prentice, and M. Saarnisto. 1980. Statistical studies on pollen representation in Finnish lake sediments in relation to forest inventory data. Annales Botanici Fennici 17:379-393.

Peters, A., and T. Webb, III. 1979. A radiocarbon-dated pollen diagram from west-central Wisconsin. Bulletin of the Ecological Society of America 60:102.

Prentice, I. C. 1978. Modern pollen spectra from lake sediments in Finland and Finnmark, north Norway. Boreas 7: 131-153.

- 1985. Pollen representation, source area, and basin size: toward a unified theory of pollen analysis. Quaternary Research 23:76-86.

- 1986. Long-term processes, response times and equilibrium in vegetation. Vegetatio 67:131-142.

Prentice, I. C., P. J. Bartlein, and T. Webb III. 1991. Vegetation and climate change in eastern North America since the last glacial maximum. Ecology 72:2038-2056.

Prentice, I. C., and T. Webb III. 1986. Pollen percentages, tree abundances and the Fagerlind effect. Journal of Quaternary Science 1:35-43.

Sharpe, D. M., G. R. Guntenspergen, C. P. Dunn, L. A. Leitner, and F. Stearns. 1987. Vegetation dynamics in a southern Wisconsin agricultural landscape. Pages 137-158 in M. G. Turner, editor. Landscape heterogeneity and disturbance. Springer-Verlag, New York, New York, USA.

Sokal, R. R. 1979. Ecological parameters inferred from spatial correlograms. Pages 167-196 in G. P. Patil and M. L. Rosenweig, editors. Contemporary quantitative ecology and related ecometrics. International Co-operative, Fairland, Maryland, USA.

Sokal, R. R., and N. L. Oden. 1978. Spatial autocorrelation in biology 1. Methodology. Biological Journal of the Linnean Society 10:199-228.

Solomon, A. M., and F. Webb III. 1985. Computer-aided reconstruction of late-Quaternary landscape dynamics. Annual Review of Ecology and Systematics 16:63-84.

Upton, G. J. G., and B. Fingleton. 1985. Spatial data analysis by example. Volume 1 . Point pattern and quantitative data. John Wiley \& Sons, New York, New York, USA.

Webb, S. L. 1983. The Holocene extension of the range of American beech (Fagus grandifolia) into Wisconsin: paleoecological evidence for long-distance seed dispersal. Thesis. University of Minnesota, Minneapolis, Minnesota, USA.

Webb, T., III. 1974. A vegetation history from northern Wisconsin: evidence from modern and fossil pollen. American Midland Naturalist 92:12-34.

1981. 11000 years of vegetational change in eastern North America. BioScience 31:501-506.

. 1986. Is vegetation in equilibrium with climate? How to interpret late-Quaternary pollen data. Vegetatio 67: 75-91.

- 1987. The appearance and disappearance of major vegetational assemblages: long-term vegetational dynamics in eastern North America. Vegetatio 69:177-187.

- 1988. Eastern North America. Pages 385-414 in B. Huntley and T. Webb III, editors. Vegetation history. Kluwer Academic, Dordrecht, The Netherlands.

Webb, T., III, P. J. Bartlein, S. P. Harrison, and K. A. Anderson. 1993. Vegetation, lake levels, and climate in North America for the past 18,000 years. In H. E. Wright, Jr., T. Webb III, F. A. Street-Perrott, W. F. Ruddiman, J. E. Kutzbach and P. J. Bartlein, editors. Global climates for 9000 and 6000 years. University of Minnesota Press, Minneapolis, Minnesota, USA, in press.

Webb, T., III, and R. A. Bryson. 1972. Late- and postglacial climatic change in the northern Midwest, U.S.A.: Quantitative estimates derived from fossil pollen spectra by multivariate statistical analysis. Quaternary Research 2:70-115.

Webb, T., III, E. J. Cushing, and H. E. Wright, Jr. $1983 a$. Holocene changes in the vegetation of the Midwest. Pages 142-165 in H. E. Wright, Jr., editor. Late-Quaternary environments of the United States. University of Minnesota Press, Minneapolis, Minnesota, USA.

Webb, T., III, S. E. Howe, R. H. W. Bradshaw, and K. M. 
Heide. 1981. Estimating plant abundances from pollen data: the use of regression analysis. Review of Palaeobotany and Palynology 34:269-300.

Webb, T., R. A. Laseki, and J. C. Bernabo. 1978. Sensing vegetation patterns with pollen data: choosing the data. Ecology 59:1151-1163.

Webb, T., III, P. Richard, and R. J. Mott. 1983b. A mapped history of Holocene vegetation in southern Quebec. Syllogeus 49:273-336.
Whitney, G. G. 1986. Relation of Michigan's presettlement pine forests to substrate and disturbance history. Ecology 67:1548-1559.

Woods, K. D., and M. B. Davis. 1989. Paleoecology of range limits: beech in the Upper Peninsula of Michigan. Ecology 70:681-696. 